người bệnh đái tháo đường type 2 điều trị ngoại trú tại Bềnh viện Nội tiết tỉnh Băc Giang năm 2019 Khoa hoc Điều dưỡng, 2019, tr. 97-104.

2. Vinh Phạm Nguyênn, Đái Tháo Đường và bệnh Mach Và̀nh: tâm quan trọng của kiểm soát tích cực LDL-C, Hội nghị khoa học toàn quốc lần VI của hội Nồi tiết và Đái tháo đường Viêt Nam, 2012, tr. 152.

3. Aljack HA, High Sensitive C Reactive Protein in Sudanese Type 2 Diabetic Patients, Sudan Journal of Medical Sciences, 2019, pp. 132-142.

4. Elimam $\mathbf{H}$ et al., Inflammatory markers and control of type 2 diabetes mellitus, Diabetes \& Metabolic Syndrome: Clinical Research \& Reviews, 2018, pp. 800-804.

5. Kashinakunti SV, Serum High Sensitive - C Reactive Protein Levels in Type 2 Diabetes Mellitus
-A Case Control Study, International Journal of Biochemistry Research \& Review, 2016, pp. 1-8.

6. Roopakala MS, Evaluation of high sensitivity creactive protein and glycated hemoglobin levels in diabetic nephropathy, Saudi Journal of kidney diseases and transplantation, 2012, pp. 286.

7. Singh $\mathbf{M}$, High-sensitivity $\mathbf{C}$-reactive protein, Malondialdehyde and their association with Glycated hemoglobin (HbA1c) in type 2 diabetes patients, International Journal of Health and Clinical Research, 2020, pp. 81-86.

8. Singh $\mathbf{N}$, A cross-sectional study on association of high-sensitivity C-reactive proteins (HS-CRP) with dyslipidemia in type 2 diabetic patients of Haryana region, International J. of Healthcare and Biomedical Research, 2019, pp. 30-39.

\title{
ĐặC ĐIỂM LÂM SÀNG CỦA HộI CHỨNG SẢNG CẤP DẠNG KÍCH ĐộNG Ở BÊ̂NH NHÂN NGộ ĐộC CẤP
}

\section{TÓM TẮT}

Mục tiêu: Mô tả đăc điểm lâm sàng của hôii chứng sảng cấp dạng kích động ở bệnh nhân ngộ độc cấp tại Trung tâm chống độc Bệnh viện Bạch Mai. Phương pháp: Nghiên cứu mô tả tiến cứu trên 48 bệnh nhân có hội chứng sảng cấp dạng kích động do ngộ độc cấp tại trung tâm chống độc,Bệnh viện Bạch Mai từ tháng 1 năm 2020 tới tháng 10 năm 2021. Kết quả: Trong số bệnh nhân nghiên cứu, nam chiếm 72,9\%, gặp nhiều nhất ở nhóm tuổi 18-19 (64,6\%), đa số là lao động tự do $(71,7 \%)$. Tỷ lệ triệu chứng lâm sàng kích động với mức độ nặng là $100 \%$. Các triệu chứng thường gặp là không sợ đau $(50 \%)$, thở nhanh $(97,7 \%)$, vã mồ hôi $(70,8 \%)$, không làm theo lệnh $(83,3 \%)$, tăng cường cơ $(81,3 \%)$, mêtt mỏi $(77,1 \%)$, tăng thân nhiệt $(85,4 \%)$, quần áo không phù hợp $(54,6 \%)$, co giât $(31,3 \%)$, tăng phản xa gân xương $(72,9 \%)$, giãn đồng tử $(56,3 \%)$ và run $(47,9 \%)$, tăng trương lực cơ $(79,2 \%)$, huyết áp tâm thu trung bình $135,0 \pm 10,6 \mathrm{mmHg}$, nhịp tim trung bình là 120,4 \pm 13,9. Kết luận: Hội chứng sảng cấp dang kích động ở bệnh nhân ngộ độc cấp là một cấp cứu lâm sàng với biểu hiên mức độ kích động nặng, nhiều triệu chứng thực tổn nặng như tăng thân nhiệt, tăng trương lực cớ, co giât... cân được xác đinh và xứ trí nhanh chóng.

Tư khóa: Hội chứng sảng cấp dạng kích động, ngộ độc cấp

\footnotetext{
${ }^{1}$ Trường Đại học Y Hà Nội,

2Trung tâm Chống độc,

${ }^{3}$ Viện sức khỏe tâm thần quốc gia,

${ }^{4}$ Bềnh viện đa khoa tỉnh Vînh Phúc

Chịu trách nhiệm chính: Đỗ Đình Lượng

Email: dodinhluong28108@gmail.com

Ngày nhận bài: 23.8.2021

Ngày phản biên khoa hoc: 25.10.2021

Ngày duyệt bài: 2.11.2021
}

Đỗ Đình Lượng ${ }^{1,4}$, Đặng Thị Xuân², Nguyễn Văn Tuấn ${ }^{1,3}$, Hà Trần Hưng ${ }^{1,2}$

\section{SUMMARY \\ CLINICAL FEATURES OF EXCITED DELIRIUM SYNDROME IN ACUTE POISONINGS}

Objectives: to describe the clinical characteristics of acute delirium agitation in acute poisoned patients at Vietnam Poison Control Center, Bach Mai Hospital. Methods: A prospective observational study included 48 patients with acute delirium due to acute poisoning at the Poison Control Center from January 2020 to October 2021. Results: most of the study patients were male $(72.9 \%)$, in the age group of $18-19$ years old $(64.6 \%)$, and unemployed $(71.7 . \%)$. The rate of severe agitation was $100 \%$. The common symptoms were: not afraid of pain $(50 \%)$, rapid breathing $(97.7 \%)$, sweating $(70.8 \%)$, not following orders $(83.3 \%)$, increase in muscle strength $(81.3 \%)$, loss of fatigue $(77.1 \%)$, increase in body temperature $(85.4 \%)$, inappropriate clothing (54.6), delusions of harm $(54.3 \%)$, delusions of jealousy $(2.2 \%)$, panic attacks of pride $(2.3 \%)$, no delusions $(41.3 \%)$, patients have hallucinations $43.8 \%$, hallucinations visual acuity $25.0 \%$ without hallucinogenic disorder $31.2 \%$, mean systolic blood pressure was $135.0 \pm 10.6$, mean heart rate was $120.4 \pm 13.9$. Conclusion: Agitated delirium syndrome in acute poisoned patients was a clinical emergency with severe agitation, many serious signs such as hyperthermia, increased muscle tone, convulsions, etc. required prompt identified and treated.

Keywords; Excited delirium syndrome, acute poisoning

\section{I. ĐĂT VẤN ĐỀ}

Hội chứng sảng cấp dạng kích động (Excited Delirium syndrome ExDS) theo Hiệp hội bác sĩ cấp cứu Hoa Kỳ (ACEP-American of college emergency physician) được định nghĩa là một tình trạng sảng cấp kết hợp với hoạt động dữ dội 
về thể chất và kích động về tâm thần ${ }^{1}$. Sảng cấp dạng kích động (SCDKĐ) với sự kích động bạo lực và hành vi quá khích là một trong những vấn đề thường xảy ra ở khoa cấp cứu. Nguyên nhân gây SCDKĐ thường gặp trong cấp cứu gồm có do ngộ độc các chất kích thích như cocain, amphetamine, LSD, cần sa, rượu.., và ít hơn là các bệnh lý tâm thần (như hưng cảm trầm cảm và tâm thần phân liệt). Cơ chế của sảng dạng kích động chưa được hiểu biết rõ ràng,trong khi điều trị chưa có thuốc điều trị đặc hiệu. Cùng với việc lạm dụng các chất kích thích ngày càng tăng thì ngộ độc do sử dụng các chất kích thích ngày càng gặp nhiều hơn. Nếu không kiểm soát được tình trạng SCDKĐ có thể dẫn tới tăng thân nhiệt, tiêu cở vân, toan chuyển hóa và những cái chết đột ngột của bệnh nhân cũng như hành động kích động gây nguy hiểm của bệnh nhân cho nhân viên $y$ tế và người nhà bệnh nhân. Tỷ lệ tử vong tùy theo các nghiên cứu được báo cáo từ 8-10\%. ${ }^{2}$ Nghiên cứu ở Việt Nam về lâm sàng của hội chứng SCDKĐ do ngộ độc còn chưa nhiều. Vì vậy chúng tôi tiến hành nghiên cứu này với mục tiểu mô tả đặc điểm lâm sàng của hội chứng sảng cấp dạng kích động trong ngộ độc cấp.

\section{II. ĐỐI TƯợNG VÀ PHƯƠNG PHÁP NGHIÊN CỨU \\ 2.1 Đối tượng nghiên cứu}

Tiêu chuẩn lựa chọn: Các bệnh nhân có biểu hiện SCDKĐ do ngộ độc cấp điều trị tại Trung tâm chống độc Bệnh viện Bạch Mai từ tháng 1/2020 tới 8/2021.

Tiêu chuẩn loại trừ: Các bệnh nhân CTSN, nhiễm trùng TKTW, tai biến mạch máu não, ra viện vẫn không xác định được nguyên nhân, bệnh nhân không đồng ý tham gia nghiên cứu.

\subsection{Thời gian địa điểm nghiên cứu:}

Thời gian nghiên cứu: Từ tháng 1/2020 đến tháng 10/2021

Địa điểm nghiên cứu: Trung tâm chống độc Bệnh viện Bạch Mai.

2.2 Thiết kế nghiên cứu: Nghiên cứu mô tả tiến cứu

2.4 Cỡ mẫu nghiên cứu: Tất cả bệnh nhân vào điều trị tại Trung tâm chống độc trong thời gian nghiên cứu phù hợp với tiêu chuấn lựa chọn. có tất cả 48 bệnh nhân.

2.5 Tiến hành nghiên cứu: Bệnh nhân ngộ độc cấp có biểu hiện sảng cấp dạng kích động ( $\geq 6 / 10$ theo tiêu chuẩn chẩn đoán của ACEP) được khám đánh giá các triệu chứng về tâm thần, thần kinh, tim mạch, hồ hấp và các triệu chứng cơ quan khác phối hợp.

2.6 Phân tích số liệu: Số liệu được phân tích bằng phần mềm thống kê SPSS 20.0. dữ liệu được trình bày dưới dạng tần số và tî lệ phẩn trăm với biến định tính, dạng trung bình \pm độ lệch chuẩn hoặc trung vị (tứ phân vị) với biến định lượng.

\section{KẾT QUẢ NGHIÊN CỨU}

Trong thời gian nghiên cứu có tất cả 48 bệnh nhân đủ tiêu chuẩn lựa chọn. Hội chứng SCDKĐ thường gặp nhất ở nhóm có độ tuổi từ 18-39 $(64,6 \%)$, nhóm từ 40-60 tuổi chiếm $18,8 \%$, nhóm $\geq 60$ tuổi $3,1 \%$. Trong đó trẻ nhất là 18 tuổi và nhiều tuối nhất 70 tuổi, độ tuổi trung bình là $31,2 \pm 13,1$. Trong số bệnh nhân nghiên cứu thì chủ yếu gặp nam giới (35 bệnh nhân chiếm $72,9 \%$ ). Bệnh nhân lao động tự do số lượng nhiều nhất (35 bệnh nhân tỷ lệ $72,9 \%$ ), học sinh, sinh viên có 11 bệnh nhân với tỷ lệ $22,9 \%$, nông dân 1 bệnh nhần và công chức 1 bệnh nhân tỷ lệ mỗi loại 2,1\%.

Đặc điểm lâm sàng của hội chứng sảng cấp dạng kích động

3.1 Tỷ lệ các triệu chứng trong hội chứng sảng cấp dạng kích động theo ACEP

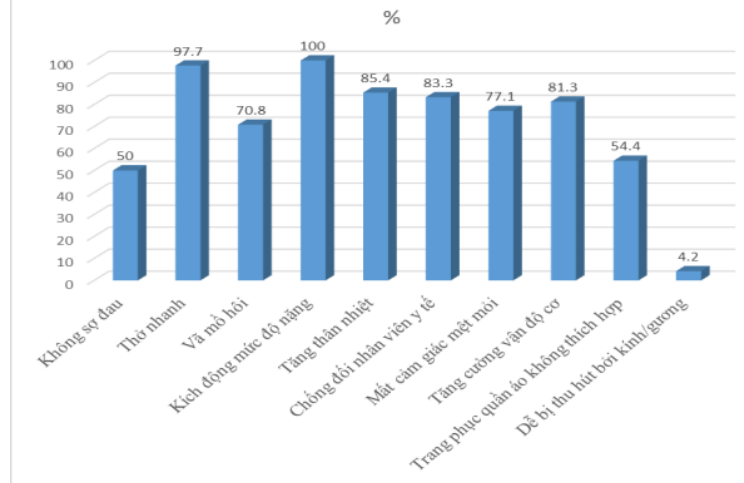

Biểu đồ 1. Đặc điểm tỷ lệ các triệu chứng trong hội chứng sảng cấp dạng kích động

Nhận xét: Trong 10 triệu chứng chẩn đoán sảng cấp dạng kích động theo $\mathrm{AECP}$ thì gặp nhiều nhất triuệ chứng kích động $100 \%$, và ít nhất là triệu chứng thu hút bởi kính gương 4,2\%.

3.2 Mức độ kích động trong sảng cấp dạng kích động

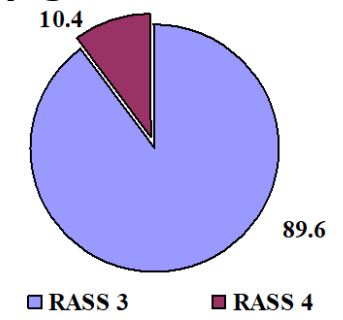

Biêu đồ 2. Tỷ lệ mức độ kích động trong hội chứng sảng cấp dạng kích động 
Nhận xét: Kích động gặp trong sảng cấp dạng kích động chủ yếu mức độ nặng, trong đó RASS+3 là 89,6\%, RASS+4 10,4\%.

3.3. Đặc điểm các triệu chứng tâm thân kinh khác

Bảng 1. Đắc điểm các triệu chứng tâm thần kinh khác

\begin{tabular}{|c|c|c|}
\hline Triệu chứng & Số lượng & $\mathbf{\%}$ \\
\hline Tăng trương lực cơ & 38 & 79,2 \\
\hline Tăng phản xạ gân xương & 35 & 72,9 \\
\hline Ao giác & 33 & 68,8 \\
\hline Hoang tưởng & 28 & 58,7 \\
\hline Đônng tứ giãn & 27 & 56,3 \\
\hline Run & 23 & 47,9 \\
\hline Co giật & 10 & 31,3 \\
\hline
\end{tabular}

Nhận xét: Thường gặp nhất là dấu hiệu tăng trương lực cơ và tăng phản xạ gân xương. Hoang tưởng và ảo giác cũng thường gặp $(58,7 \%$ và $68,8 \%)$. Có 10 bệnh nhân có biểu hiện nặng là co giật (31,3\%).

Bảng 2. Đặc điếm tîm mạch trong sảng câp dạng kích động

\begin{tabular}{|c|c|c|c|}
\hline $\begin{array}{c}\text { Triếu } \\
\text { chứng }\end{array}$ & $\begin{array}{c}\text { Thấp } \\
\text { nhất }\end{array}$ & $\begin{array}{c}\text { Lớn } \\
\text { nhất }\end{array}$ & TB \pm ĐLC \\
\hline Mạch & 105 & 160 & $120,4 \pm 13,9$ \\
\hline HA Tầm thu & 120 & 160 & $135,0 \pm 10,6$ \\
\hline HA tâm trương & 60 & 100 & $84,7 \pm 8,02$ \\
\hline Nhiệt độ & 36,8 & 38,8 & $37,6 \pm 0,4$ \\
\hline
\end{tabular}

Nhận xét: Với tình trạng kích động các biếu hiên về Mach và HATT và HATTr đều tăng. Nhiêt độ trung bình $37,6 \pm 0,4$, cao nhất $38,8^{\circ} \mathrm{C}$.

\section{BÀN LUÂ̂N}

Trong nghiên cứu của chúng tôi có 48 bệnh nhân mắc hội chứng sảng cấp dạng kích động độ tuổi trong nghiên cứu từ 18 - 70 tuổi, nhóm tuổi mắc nhiều nhất là nhóm từ 18-39 tuổi với tỷ lệ $66,4 \%$ với độ tuổi trung bình là 31 tuổi tương tự với phân tích gộp của Goin và cộng sự với độ tuổi mắc của sảng cấp dạng kích động là 14- 71 tuổi với độ tuổi trung bình mắc là 33 tuổi. ${ }^{2}$ Đặc điểm của bệnh nhân về giới tính trong nghiển cứu chúng tôi gặp chủ yêu bệnh nhân là nam giới với tỷ lệ $72,9 \%$, nữ giới chiếm tỷ lệ $27,1 \%$ tương đồng với nghiên cứu của Iwanicki JL, và cộng sự thì tỷ lệ nam giới là $83 \%$ và $17 \%$ là nữ. ${ }^{3}$

Trong nghiên cứu của chúng tôi triệu chứng không sợ đau 24 bệnh nhân (50\%), thở nhanh có 47 bệnh nhân $(97,7 \%)$, vã mồ hôi có 34 bệnh nhân $(70,8 \%)$, kích động có 48 bệnh nhân $(100 \%)$, không làm theo y lệnh có 40 bệnh nhân (83,3\%), tăng cướng độ vận cơ có 39 bệnh nhân $(81,3 \%)$, mất cảm giác mệt mỏi có 37 bệnh nhân $(77,1 \%)$, tăng thân nhiệt có 41 bệnh nhân 85,4\%, trang phục không phù hợp 26 bệnh nhân
$(54,6)$, có 2 bệnh nhân bị thu hút bởi gương, kính $(4,2 \%)$. So sánh với tần suất gặp các triệu chứng của SCDKĐ theo ACEP bệnh nhân không sợ đau $100 \%$, thở nhan $100 \%$, vã mồ hôi $95 \%$, kích động $95 \%$, tăng thân nhiệt $95 \%$, không làm theo y lệnh $90 \%$, vận động không mệt mỏi 90\%, tăng vận cơ $90 \%$, quần áo không thích hợp $60 \%$, thu hút bởi gương, kính $10 \% .{ }^{1}$

Mức độ kích động trong sảng cấp dạng kích động được đánh giá theo thang điểm RASS, trong nghiên cứu của chúng tôi có $43(89,6 \%)$ bệnh nhân RASS +3 và $3(11,4 \%)$ bệnh nhân RASS +4. Trong nghiên cứu Helmer ] có 33 bênh nhân bệnh thì bệnh nhân RASS +4 có 20 bểnh nhân $60,0 \%$, bệnh nhân RASS +3 có 13 bểnh nhân chiếm $39,9 \% .{ }^{4}$ Ngoài ra các triệu chứng tâm thần kinh khác như 10 bệnh nhân co giật $(31,3 \%)$, có tăng phản xạ gân xương $(72,9 \%)$, đồng tử giãn 27 bệnh nhân $(56,3 \%)$ và run 23 bệnh nhân \% (47,9\%), tăng trương lực cơ 38 $(79,2 \%)$. Trong đó co giật là triệu chứng đi cùng có thể gây nguy hiểm tính mạch cho bệnh nhân, ngoài ra co giật, run, tăng trương lực cơ, kích động cung với tăng thân nhiệt gây mất nước có thể dẫn tới tiêu cơ vân, suy thận cấp.Trong ngiên cứu của Ruttenber AJ co giật ở bệnh nhân SCDKĐ 27\%.

Huyết áp tâm trương tại thời điểm SCDKĐ trung bình là $84,7 \pm 8,02$, thấp nhất $65 \mathrm{mmHg}$, cao nhất $100 \mathrm{mmHg}$, Huyết áp tâm thu trung bình $135,0 \pm 10,6$ cao nhất lúc vào $160 \mathrm{mmHg}$, thấp nhất $120 \mathrm{mmHg}$, Mạch trung bình 120,4 \pm 13,9 cao nhất 160 lầ/phút, thấp nhất 105 lần/phút. Nhiệt độ trung bình $37,6 \pm 0,4$, cao nhất $38,8^{\circ} \mathrm{C}$. Trong nghiên cứu của Thomas R.Scaggs thấy huyết áp tâm trương trung bình lúc vào của bệnh nhân là $86 \mathrm{mmHg}$, huyết áp tâm thu trung bình là $148 \mathrm{mmHg}$ và mạch trung bình 128 lần/phút. ${ }^{5}$

\section{KẾT LUÂN}

Hội chứng sảng cấp dạng kích động ở bệnh nhân ngộ độc cấp là một cấp cứu lâm sàng với biểu hiện mức độ kích động nặng, nhiều triệu chứng thực tổn nặng như tăng thân nhiệt, tăng trường lực cớ, co giật... cần được xác định và xử trí nhanh chóng.

\section{TÀI LIỆU THAM KHẢO}

1. White Paper Report on Excited Delirium Syndrome (ACEP) | Diseases And Disorders | Health Care. Scribd. Accessed July 20, 2021.

2. Gonin P, Beysard N, Yersin B, Carron PN. Excited Delirium: A Systematic Review. Academic Emergency Medicine. 2018;25(5):552-565 
3. Wanicki JL, Barrett W, Saghafi 0 , et al. Prehospital ketamine for excited delirium in the setting of acute drug intoxication. In: Toxicology Clinical. New York, NY: Informa Healthcare, 2014:685-6.

4. Helmer J, Acker J, Deakin J, Johnston $T$. Canadian paramedic experience with intramuscular ketamine for extreme agitation: A quality improvement initiative. Australasian Journal of Paramedicine. 2020;17.
5. Scaggs TR, Glass DM, Hutchcraft MG, Weir WB. Prehospital Ketamine is a Safe and Effective Treatment for Excited Delirium in a Community Hospital Based EMS System. Prehosp Disaster med. 2016;31(5):563-569.

6. Ruttenber AJ, Lawler-Heavner J, Yin $M$, et al. Fatal excited delirium following cocaine use: epidemiologic findings provide new evidence for mechanisms of cocaine toxicity. J Forensic Sci. $1997 ; 42(1): 25-31$

\section{KHẢO SÁT TỶ LÊ STAPHYLOCOCCUS AUREUS ĐỀ KHÁNG METHICILLIN (MRSA) VÀ HIỆU QUẢ PHỐI HỢP KHÁNG SINH VANCOMYCIN VỚI CEFEPIME/GENTAMICIN TRÊN CÁC CHỦNG MRSA PHÂN LẬP TẠI BỆNH VIỆN ĐA KHOA BẠC LIÊU}

Bùi Phát Đạt ${ }^{1}$, Lê Văn Chương ${ }^{2,3}$, Ngô Quốc Đạt ${ }^{2}$,

\section{TÓM TẮT}

Đặt vấn đê: Staphylococcus aureus (S. aureus) đề kháng methicillin (MRSA) được Trung tâm kiểm soát và phòng ngừa bệnh tật Hoa Kỳ liệt kê là một trong những: "Mối đe dọa về kháng thuổc kháng sinh ở Hoa Kỳ" vì mức độ nghiêm trọng và đăc tính đa kháng thuốc. Liệu pháp phối hợp kháng sinh điêuu trị MRSA hiện nay đang chỉ ra nhiều hứa hẹn. Muc tiều: Xác định tỷ lệ MRSA và khảo sát hiệu quả phối hợp kháng sinh giữa vancomycin với cefepime, vancomycin với gentamicin trên các chủng MRSA. Phương pháp nghiên cứu: Từ 125 chủng $\mathrm{S}$. aureus được định danh và làm kháng sinh đồ bằng máy tự động Vitek2 Compact, thu thâp được 111 chủng MRSA bằng MIC (nồng độ ức chể tối thiểu) cefoxitin screen có sẵn trong card AST P592. Phối hợp kháng sinh giữa vancomycin với cefepime trên 111 chủng MRSA; giữa vancomycin và gentamicin trên 53 chủng MRSA bằng phương pháp vi pha loãng (checkerboard). Kết quả: Tỷ lể MRSA chiếm $88,8 \%$. MRSA phân bố nhiều nhất ở bệnh phẩm mủ $(61,3 \%)$, dịch $(22,5 \%)$, đàm $(10,8 \%)$ và máu $(5,4 \%)$. Dựa vào chỉ số FIC (nồng độ ức chế phân đoạn), phối hợp kháng sinh vancomycin với cefepime cho kết quả hiệp đông (45\%), cộng (51,3\%), độc lập $(3,6 \%)$ và không có đối kháng. Vancomycin với gentamicin cho kết quả hiệp đồng $(39,6 \%)$, cộng $(58,5 \%)$, độc lập $(1,9 \%)$ và không có đối kháng. Kêt́ luận: Tý lệ MRSA khá cao được ghi nhận tại Bệnh viện Đa khoa Bạc Liêu. Phối hợp kháng sinh vancomycin

${ }^{1}$ Bệnh viện Đa khoa Bạc Liêu

2Đäi hoc Y Dướ TPHCM

${ }^{3}$ Trung tâm Kiểm chuẩn Chất lượng Xét nghiệm Y học, Đại hoc Y Dước TPHCM

${ }^{4}$ Bênh viên Đai hoc Y Dướ TPHCM

Chịu trách nhiệm chính: Huỳnh Minh Tuấn

Email: huynhtuan@ump.edu.vn

Ngày nhận bài: 23.8.2021

Ngày phản biên khoa hoc: 18.10.2021

Ngày duyệt bài: 28.10.2021
Hồ Ngọc Hương1, Huỳnh Minh Tuấn ${ }^{2,4}$ với cefepime, vancomycin với gentamicin cho hiệu quả hiệp đồng và cộng hợp cao trên các chủng MRSA. Kết quả nghiên cứu là cớ sở cho việc cân nhắc lựa chọn phối hợp kháng sinh của bác sĩ và là tiền đề nghiển cứu hiệu quả phối hợp kháng sinh trên lâm sàng.

Tưं khoá: S. aureus, MRSA, phối hợp kháng sinh, vancomycin, checkerboard.

\section{SUMMARY}

PREVALENCE OF METHICILLIN RESITANCE S. AUREUS AND EFFICACY OF ANTIBIOTIC COMBINATION BETWEEN VANCOMYCIN AND CEFEPIME OR GENTAMICIN AGAINST MRSA ISOLATED FROM BAC LIEU GENERAL HOSPITAL

Background: Methicillin resistant $S$. aureus (MRSA) is listed by Centers for Disease Control and Prevention as one of the: "Antibiotic Resistance Threats in the United States" because of its severity and multidrug resistance. Antibiotic combination treatment for MRSA infections has been shown promising treatment. Objective: To determine percentages detection of MRSA and efficacy of antibiotic combination between vancomycin and cefepime or gentamicin against MRSA strains. Methods: From 125 strains of S. aureus that were identified and performed routine antibiotic susceptibility testing by automated machine (Vitek2 Compact), 111 MRSA strains were determined by MIC (minimum inhibitory concentration) cefoxitin screen available in card AST-P592. In vitro antibiotic combination between vancomycin and cefepime on 111 MRSA strains; vancomycin and gentamicin on 53 MRSA strains by microdilution (checkerboard) method. Results: Prevalence of MRSA is $88.8 \%$. MRSA was most widely distributed in pus $(61.3 \%)$, fluid $(22.5 \%)$, sputum $(10.8 \%)$ and blood (5.4\%). Based on the FIC (Fractional Inhibitory Concentration) index, vancomycin-cefepime combination showed synergism $(45 \%)$, additive $(51.3 \%)$, independent $(3.6 \%)$ and no antagonism. Vancomycin-gentamicin combination 